\title{
Social approach to arsenic mitigation in Gangetic belt, India
}

\author{
S. Singh \& Chandrbhushan \\ Innervoice Foundation, Varanasi, India
}

\begin{abstract}
Arsenic contamination of groundwater from two Indian states (Bihar and Uttar Pradesh) has been reported during 2003-2004. Although several small scale studies documented the arsenic concentrations in groundwater, source of arsenic in groundwater, effect of arsenic-contaminated in food crops and the health effects due to the consumption of polluted water. Very little is known about the social approach on arsenic mitigation, which is crucial. This paper highlights the importance of social approach to arsenic mitigation.
\end{abstract}

\section{INTRODUCTION}

Arsenic contamination in groundwater of Bihar and Uttar Pradesh (UP) was documented during 20032004 (Chakraborti et al., 2003, 2004; MDWS, 2011; Mukherjee et al., 2006; Ramanathan et al., 2009). During last 15 years, various experts have been working on this topic. It has been estimated that about 2 million people are exposed and currently at risk from groundwater arsenic contamination from both Indian states. Reduction of arsenic in public water is important to minimize the exposure to human. Therefore, mitigation approach is crucial to provide arsenic-safe water to the people living in these areas (Hossain et al., 2015; SASMIT, 2014). However, immediate mitigation intervention is not possible due to the negligence of the problem, lack of acceptance of the existing problem by the government and other agencies who are responsible for the safe water supply.

In developing nations, there is lack of adequate water legislation, and periodic screening program of the drinking water is absent. Although water legislations are present, no implementations are likely to occur due to lack of awareness of the village communities and adequate capacity of the government officials in arsenic mitigation programs. Thus, arsenic mitigation efforts are often missing in the affected villages. As a result, people are suffering from various arsenical diseases due to the consumption of the arsenic contaminated water. On the other end, it can be realized that without community's active participation, it is challenging to fight against the arsenic toxicity. Therefore, we need first to educate the villagers as well as we need to train them about the effective arsenic mitigation approaches for the operative mitigation program.

\section{METHODS}

Based on the available village-wise baseline data from the study area, mapping of arsenic distribution in groundwater were conducted. The information gathered was critically analyzed to understand the current knowledge and gaps in the existing mitigation approaches followed by implementation of the effective mitigation approaches. Community-based meetings were organized with the affected villagers and local authorities to determine the problems and the existing health concerns. Their responses were evaluated and included in the viable mitigation approach to the impacted areas. This will lead to developing a holistic strategy to combat arsenic mitigation in rural parts of the Gangetic belt.

\section{RESULTS AND DISCUSSION}

Proper mapping of arsenic-contaminated sites is required involving technical experts, scientists, experts in water law, policymakers and members from affected communities. Primary and secondary level data from affected areas are required for this purpose. Reports from local newspapers could be used to form such database.

Discussion with the community will be carried out, and the results will be recorded in a questionnaire format. Assessing community's need often requires special insight at a preliminary level. Questionnaire format developed in consultation with the affected communities provides a significant understand of the real problems faced by the communities in the affected regions. From previous experience, we came to know that villagers were entirely unaware about the issue and therefore not in a position to speak on the subject at this stage as they did not know the basic facts of arsenic contamination, which was affecting their health and livelihood beyond measures. It proved to be helpful if the community is sensitized and educated on the subject at this stage. Making community speak out on the subject marked significant information/suggestion inflow on the subject (Rajya Sabha TV, 2015). Various reports in the media have proved to have considerable 
impact, as exemplified by the report on arsenic contamination in Ballia based on the complaint addressed by the affected people of Ballia. A National Level Monitor was appointed to investigate the complaint on the water quality by the Ministry of Rural Development, Government of India (India Water Portal, 2011; MDWS, 2011).

These exercises have a very positive impact on society, which also helped in ensuring their active participation in subsequent arsenic mitigation programmes. Opening up a dialogue with Central, State, and Local authorities are also crucial.

\section{CONCLUSIONS}

There is a lack of legislative structure in developing countries including India, which is necessary to address such sensitive issue. To solve this issue, we need concerted efforts apart from technological efforts. Media can play a very significant role. At this very crucial stage of 'Social Arsenicosis' program, utmost care and patience are required in choosing appropriate reports, facts and platform to gather support for the cause. Care should be taken not to offend sensibilities of any group or set of persons. Also, it can have the very negative impact on campaign build over the period.

\section{REFERENCES}

Chakraborti, D., Mukherjee, S.C., Pati, S., Sengupta, M.K., Rahman, M.M., Chowdhury, U.K., Lodh, D., Chanda, C.R., Chakraborti, A.K. \& Basu, G.K. 2003. Arsenic groundwater contamination in Middle Ganga Plain, Bihar, India: a future danger? Environ. Health Perspect. 2111(9):1194-1201.
Chakraborti, D., Sengupta, M.K., Rahman, M.M., Ahamad, S., Chowdhury, U.K., Hossain, M.A., Mukherjee, S.C., Pati, S., Saha, K.C., Dutta, R.N. \& Quamruzzaman, Q. 2004. Groundwater arsenic contamination and its health effects in the Ganga-Meghna-Brahmaputra plain. J. Environ. Monit. 6(6): $74 \mathrm{~N}-83 \mathrm{~N}$.

India Water Portal 2011. Investigation and assessment report: Arsenic in drinking water sources and related problems of Ballia district of Uttar Pradesh. http://www.indiawaterportal.org/articles/investigationand-assessment-report-arsenic-drinking-water-sourcesand-related-problems (accessed on 30 April, 2018)

MDWS 2011. Report of the Central Team on Arsenic mitigation in rural drinking water sources in Ballia district, Uttar Pradesh State. Ministry of Drinking Water and Sanitation, Government of India, New Delhi, India. 25p. (Downloadable from: http://www.mdws.gov.in/sites/default/files/ ballia-finalreport_0.pdf (accessed on 14 April, 2018).

Mukherjee, A.B., Bhattacharya, P., Jacks, G. Banerjee, D.M., Ramanathan, A.L., Mahanta, C. Chandrashekharam, D., Chatterjee, D. \& Naidu, R. 2006. Groundwater arsenic contamination in India: extent and severity. In: R. Naidu, E. Smith, G. Owens, P. Bhattacharya \& P. Nadebaum. (eds) Managing Arsenic in the Environment: From soil to human health. CSIRO Publishing, Melbourne, Australia, pp. 533-594

Ramanathan, AL., Tripathi, P., Kumar, M., Bhattacharya, P., Thunvik, R. \& Bundschuh, J. 2009. Arsenic distribution in the groundwater in Central Gangetic Plains of Uttar Pradesh, India. In: J. Bundschuh, M.A. Armienta, P. Birkle, P. Bhattacharya, J. Matschullat \& A.B. Mukherjee (eds): Natural Arsenic in Groundwater of Latin America - Occurrence, health impact and remediation. CRC Press/Balkema, Leiden, The Netherlands, pp. 215-224.

Rajya Sabha TV 2015. Special Report - Arsenic Poisoning of Water. (Pani mein zahar). (Viewable link: https://www .youtube. com/watch? $\mathrm{v}=\mathrm{GvsbS} 4 \mathrm{zzosw} \& \mathrm{t}=$ 106s (accessed on 30 April, 2018). 